\title{
8. GROWTH OF ACCRETIONARY WEDGES OFF VANCOUVER ISLAND AND OREGON ${ }^{1}$
}

\author{
G.K. Westbrook ${ }^{2}$
}

\begin{abstract}
A simple formulation for the growth of a wedge of constant taper accreting a sediment layer of given thickness and exponential decrease of porosity with depth was used to estimate the rates of growth of the accretionary wedges off Vancouver Island and Oregon. Application to the section off Vancouver Island indicates that the accreted sediments penetrated at Site 889 were added to the toe of the wedge between 0.8 and $1.1 \mathrm{Ma}$. Application to the Oregon section shows that the thickness of the accreted layer before 0.3 Ma must have been substantially less than the present $1.5 \mathrm{~km}$ for Pliocene sediments at Site 892 . For both wedges the accretion of a thick layer of sediment from the Cascadia Basin appears to have occurred over only the past few hundred thousand years, and no more than about a million years. Since the Eocene, the equivalent average thickness of the layer of sediment that has been accreted is about $0.5 \mathrm{~km}$.
\end{abstract}

\section{INTRODUCTION}

For an interpretation of the results of drilling into the accretionary wedge, it is useful to be able to estimate when a sequence penetrated by a borehole in the accretionary wedge was actually accreted. The time taken to build the accretionary wedge is an important parameter in the analysis of the geologic evolution of the continental margin.

To provide a straightforward means of making a first-order estimate of these parameters, a simple model of a wedge that accretes a layer of sediment with a given thickness and porosity/depth function has been developed. It is similar in its properties to other models developed for the purpose of calculating mass flux into the wedge and fluid outflow (e.g., Le Pichon et al., 1990; Bekins and Dreiss, 1992; Ferguson et al., 1993), but simpler and set up to provide values of quantities such as the amount that the wedge grows forward for a given amount of subduction of oceanic lithosphere. The formulation was encoded as a Microsoft Excel spreadsheet, using the Excel module Solver to find the values of variables in the equations. The derivation of the formulae is set out below.

\section{WEDGE ADVANCE INTO SEDIMENT IN WHICH POROSITY VARIES WITH DEPTH}

Figure 1 shows a model for the growth of a wedge in which the porosity varies as a function of depth. The wedge grows forward distance $X_{G}$ during the period that the subducting plate moves distance $X_{S}$. The initial cross-sectional area of the sediment added to the wedge is $\left(X_{G}+X_{S}\right) t$, where $t=$ the thickness of the accreted layer, $w=$ the width of the wedge before the increment of growth, and $\alpha=$ the angle of taper of the wedge.

The cross-sectional area of sediment accreted to the wedge decreases in response to porosity reduction produced by deeper burial beneath the thickening wedge, as the wedge continues to grow.

Porosity as a function of depth is equal to

$$
\varphi_{z}=\varphi_{0} \mathrm{e}^{\frac{-z}{\lambda}},
$$

where $\varphi_{0}=$ porosity at the surface, and $\lambda$ is the depth at which porosity is $1 / \mathrm{e}$ times porosity at the surface.

\footnotetext{
${ }^{1}$ Westbrook, G.K., Carson, B., Musgrave, R.J., et al., 1994. Proc. ODP, Init. Repts. 146 (Pt. 1): College Station, TX (Ocean Drilling Program).

${ }^{2}$ School of Earth Sciences, University of Birmingham, Birmingham B15 2TT, United Kingdom.
}

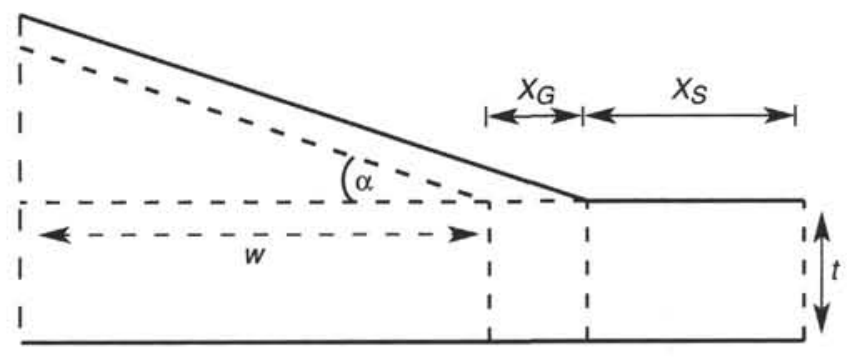

Figure 1. Principal parameters for the growth of the accretionary wedge. The initial width is $w$. The angle of taper is $\alpha$. The thickness of the accreted layer is $t$. The wedge grows outward a distance $X_{G}$, for a distance of plate convergence (subduction) $X_{S}$.

The volume of fluid per unit area, over the depth range $Z_{1}$ to $Z_{2}$, is equal to

$$
\varphi_{0} \int_{Z_{1}}^{z_{2}} \mathrm{e}^{\frac{-z}{\lambda}} d z
$$

$$
\begin{gathered}
\varphi_{0}\left[c-\lambda \mathrm{e}^{\frac{-z}{\lambda}}\right]_{Z_{1}}^{Z_{2}} \\
\varphi_{0} \lambda\left(\mathrm{e}^{\frac{-Z_{1}}{\lambda}}-\mathrm{e}^{\frac{-Z_{2}}{\lambda}}\right) .
\end{gathered}
$$

The volume of solid per unit area over the same depth range $Z_{1}$ to $Z_{2}$ is equal to

$$
Z_{2}-Z_{1}-\varphi_{0} \lambda\left(\mathrm{e}^{\frac{-Z_{1}}{\lambda}}-\mathrm{e}^{\frac{-Z_{2}}{\lambda}}\right)
$$

\section{Relationship Between Forward Growth of Wedge, Subduction Rate, and Porosity Function}

Figure 2 shows the basis for the derivation of the relationship between the cross-sectional area of enlarged part of wedge with changed porosity $\left(A_{W}\right)$ and the cross-sectional area of the sediment on 
the ocean floor moved into the wedge by subduction $\left(A_{S}\right)$. Although the cross-sectional areas are different, the solid portions of the crosssectional areas $\left(A_{W \text { Solid }}\right.$ and $\left.A_{\text {S.Solid }}\right)$ are equal.

$$
\begin{aligned}
& A_{W \text {.Solid }}=\int_{0}^{x_{G}}(w+x) \tan \alpha+ \\
& t-t-\varphi_{0} \lambda\left(\mathrm{e}^{\frac{-t}{\lambda}}-\mathrm{e}^{\frac{-|(w+x) \tan \alpha+t|}{\lambda}}\right) d x \\
& =\int_{0}^{x_{G}}(w+x) \tan \alpha-\varphi_{0} \lambda \mathrm{e}^{\frac{-t}{\lambda}}\left(1-\mathrm{e}^{\frac{-\lceil(w+x) \tan \alpha]}{\lambda}}\right) d x \\
& =\left[\frac{x^{2} \tan \alpha}{2}+w x \tan \alpha-x \varphi_{0} \lambda \mathrm{e}^{\frac{-t}{\lambda}}+\right. \\
& \left.\varphi_{0} \lambda \mathrm{e}^{\frac{-(t+w \tan \alpha)}{\lambda}}\left(\frac{-\lambda \mathrm{e}^{\frac{-x \tan \alpha}{\lambda}}}{\tan \alpha}\right)\right]_{0}^{X_{\sigma}} \\
& =\frac{X_{G}^{2}}{2} \tan \alpha+w X_{G} \tan \alpha-X_{G} \varphi_{0} \lambda \mathrm{e}^{\frac{-t}{\lambda}}+ \\
& \frac{\varphi_{0} \lambda^{2}}{\tan \alpha} \mathrm{e}^{\frac{-(t+w \tan \alpha)}{\lambda}}\left(1-\mathrm{e}^{\frac{-X_{G} \tan \alpha}{\lambda}}\right) . \\
& A_{W \text {.Solid }}=A_{\text {S.Solid }}=X_{S}\left[t-\varphi_{0} \lambda\left(1-\mathrm{e}^{\frac{-1}{\lambda}}\right)\right] .
\end{aligned}
$$

Hence, the amount of subduction required to allow the wedge to grow forward by $X_{G}$ is determined from the following:

$$
\begin{gathered}
X_{S}=\left\{\frac{X_{G}^{2}}{2} \tan \alpha+w X_{G} \tan \alpha-X_{G} \varphi_{0} \lambda \mathrm{e}^{\frac{-t}{\lambda}}+\right. \\
\left.\frac{\varphi_{0} X_{G}^{2} \mathrm{e}}{\tan \alpha} \frac{-(t+w \tan \alpha)}{\lambda}\left(1-\mathrm{e}^{\frac{-X_{G} \tan \alpha}{\lambda}}\right)\right\} /\left[t-\varphi_{0} \lambda\left(1-\mathrm{e}^{\frac{-t}{\lambda}}\right)\right] .
\end{gathered}
$$

Up to this point in the derivation, no assumptions have been made about how the new sediment is added to the wedge or how the sediment moves within the wedge. As long as the sediment is accreted in a self-similar manner from a layer of constant thickness, then the relationship between the amount of forward growth of the wedge and the amount of plate convergence is given by the equation above. An underlying assumption in the derivation has been that the function of porosity with depth is everywhere the same. It is a common observation, however, that the toes of wedges are undercompacted relative to the sedimentary section of the ocean floor, and that the most landward sections of wedges are relatively overcompacted. The consequence of this would be that in very young wedges in which undercompaction predominated, the amount of forward growth would be underestimated, and that in old overcompacted wedges the amount of forward growth would be overestimated. This effect would be most prominent where

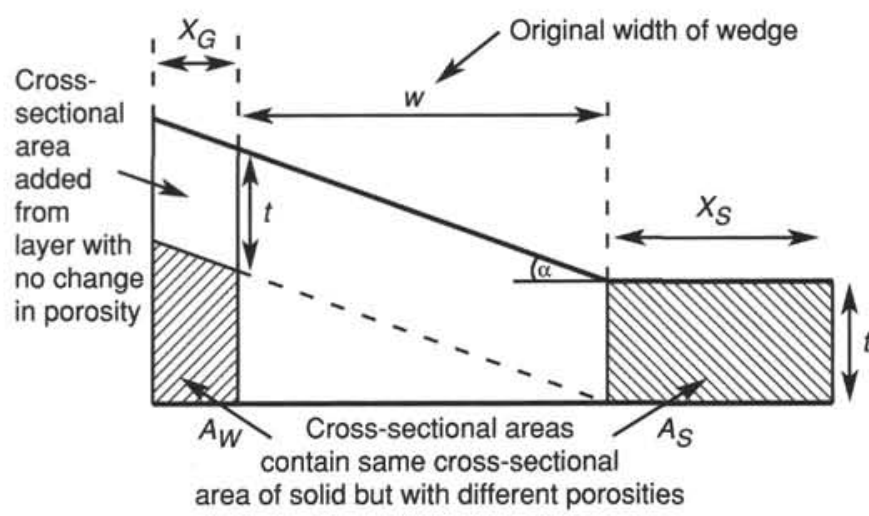

Figure 2. Illustration of the basis of the calculation for the amount that the wedge grows outward $X_{G}$ for a given amount of plate convergence $X_{S}$. The shaded areas contain the same amount of solid material, but they have different porosities because of their different depths and shapes. The white areas of the figure have the same porosities as they did before new material was accreted.

the thickness of the accreted layer is small and the differences in porosities between the different functions have their greatest effect upon the amount of solid material that is accreted. Using different porosity functions for the Cascadian accretionary wedges does not have a very great effect upon the amounts of growth, as will be shown below.

When it comes to predicting which parts of an accretionary wedge were accreted at which time, it is then necessary to adopt a model for how the sediment "flows" into the wedge as it is accreted. A simple model is one in which the accreted section is represented by a vertically sided block of sediment, the width of which decreases progressively with advance into the wedge in response to the increase in its height and the decrease in its cross-sectional area from porosity reduction (Fig. 3). The effects of horizontal displacements produced by thrusts and folds, and the effects of greater compaction in the lower part of the wedge will in nature produce departures from this simple model. These are to some extent compensating effects. Thrusting moves components of the upper part of the wedge relatively seaward, and greater compaction of the lower part of the accreted section could, in some models (Bekins and Dreiss, 1992), reduce its rate of flow into the wedge, which is also a relative seaward motion. The important point to be made is that the simple model developed here should not be used in too detailed a manner. For example, the horizontal displacements on thrusts in the toe of the wedge off Vancouver Island are about $1 \mathrm{~km}$, which places a lower limit on the resolution of the approach.

The derivation of the method for finding how far sediment moves into the wedge during a given period of accretion follows.

The total solid mass added to the wedge is equal to

$$
\left(X_{G}+X_{S}\right)\left[t-\varphi_{0} \lambda\left(1-\mathrm{e}^{\frac{-t}{\lambda}}\right)\right] .
$$

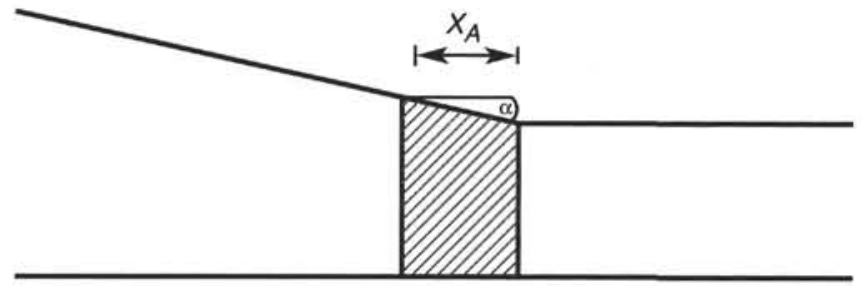

Figure 3. In a simple model of accretion, the cross-sectional area of new material added to the toe of the wedge is spread over horizontal distance $X_{A}$. 
This new mass occupies the frontal part of the wedge over a distance $X_{A}$ from the toe (Fig. 3). Its solid cross-section is equal to

$$
\begin{aligned}
& \int_{0}^{X} t+x \tan \alpha-\varphi_{0} \lambda\left(1-\mathrm{e} \frac{-(t+x \tan \alpha)}{\lambda}\right) d x \\
= & {\left[x t+\frac{x^{2}}{2} \tan \alpha-x \varphi_{0} \lambda+\frac{\varphi_{0} \lambda^{2} \mathrm{e}^{\frac{-t}{\lambda}} \mathrm{e}^{\frac{-x \tan \alpha}{\lambda}}}{\tan \alpha}\right]_{0}^{X_{A}} } \\
= & X_{A} t+\frac{X_{A}^{2}}{2} \tan \alpha-X_{A} \varphi_{0} \lambda+\frac{\varphi_{0} \lambda^{2} \mathrm{e}^{\frac{-t}{\lambda}}}{\tan \alpha}\left(1-\mathrm{e} \frac{-X_{A} \tan \alpha}{\lambda}\right) .
\end{aligned}
$$

Hence, the material at the toe of the wedge at the beginning of the accretion increment will be $X_{A}$ back from the toe at the end of the accretion increment.

More generally, the movement and change in volume of any segment of the wedge can be tracked by solving for the width of the segment while conserving the solid mass. The water lost from the segment over any increment is the change in the total cross-sectional area of the segment.

For material added in one increment to the toe, we can find $X_{A}$ from

$$
\begin{gathered}
\left(X_{G}+X_{S}\right)\left[t-\varphi_{0} \lambda\left(1-\mathrm{e}^{\frac{-t}{\lambda}}\right)\right]= \\
X_{A} t+\frac{X_{A}^{2}}{2} \tan \alpha-X_{A} \varphi_{0} \lambda+\frac{\varphi_{0} \lambda^{2} \mathrm{e}^{\frac{-t}{\lambda}}}{\tan \alpha}\left(1-\mathrm{e}^{\frac{-X_{A} \tan \alpha}{\lambda}}\right) .
\end{gathered}
$$

The fluid lost in this increment is equal to

$$
\left(X_{G}+X_{S}\right) t-X_{A} t-\frac{X_{A}^{2} \tan \alpha}{2} \text {. }
$$

In the explanations of the general model for the growth of the wedge and the more specific model for establishing the age of accretion of elements of the accretionary wedge, given above, the newly accreted material was shown as a simple vertically sided prism. This is not, however, a requirement of these models. The shape of the accretion surface can take any form, as long as it does not change (Fig. 4). In other words, the only requirement is that the mode of propagation of the wedge is self similar. So, different angles and shapes of accretionary faults or a ramp-flat geometry can all be accommodated, because they do not affect the cross-sectional area or the relative amounts of sediment with different porosity added with each accretion increment.

\section{APPLICATION TO THE VANCOUVER ISLAND MARGIN}

Off Vancouver Island, the width of the accretionary wedge beneath the continental slope and the outer part of the Tofino Basin, back to the edge of the Crescent Terrane where the wedge is about $10 \mathrm{~km}$ thick, is about $50 \mathrm{~km}$ (Hyndman et al., 1990). The thickness of the sediment on the ocean floor in front of the wedge is about $2.5 \mathrm{~km}$, above the décollement that appears to lie just above the igneous oceanic crust. Virtually all of the incoming sediment is accreted to the toe of the wedge. The overall angle of taper of the wedge is $8.5^{\circ}$ (see Fig. 2 in "Introduction" chapter, this volume). The porosity-depth function used by Davis et al. (1990) in their analysis of compaction-

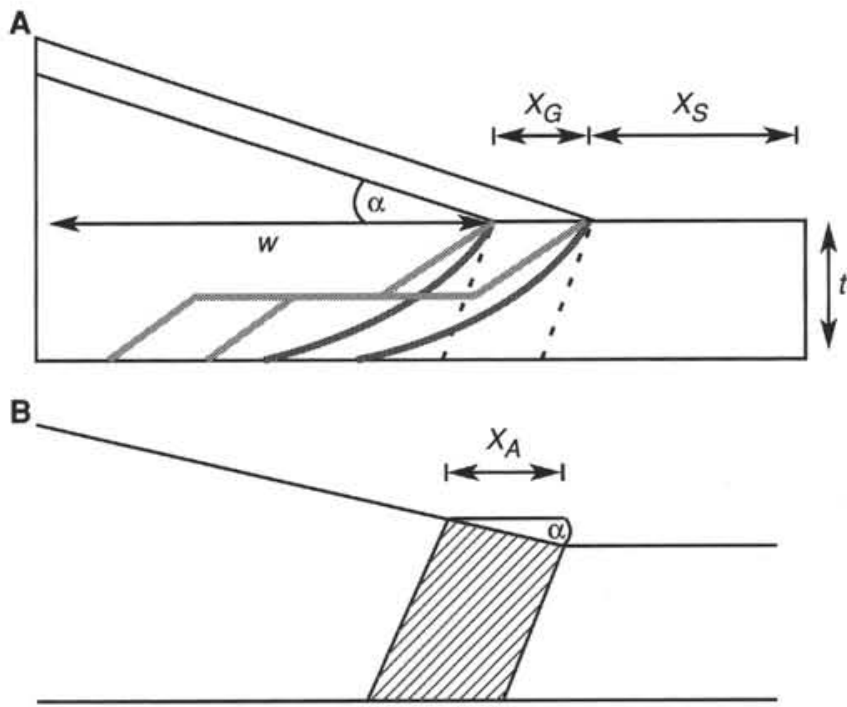

Figure 4. The shape of the accretionary surface (the interface between the accretionary wedge and the incoming sediment) does not affect the model, as long as the shape does not change with time. A. Possible variants to the geometry of Figure 1. B. Variant of Figure 3. $X_{A}$ is independent of the shape of the accreted material as long as its outer and inner surfaces are parallel.

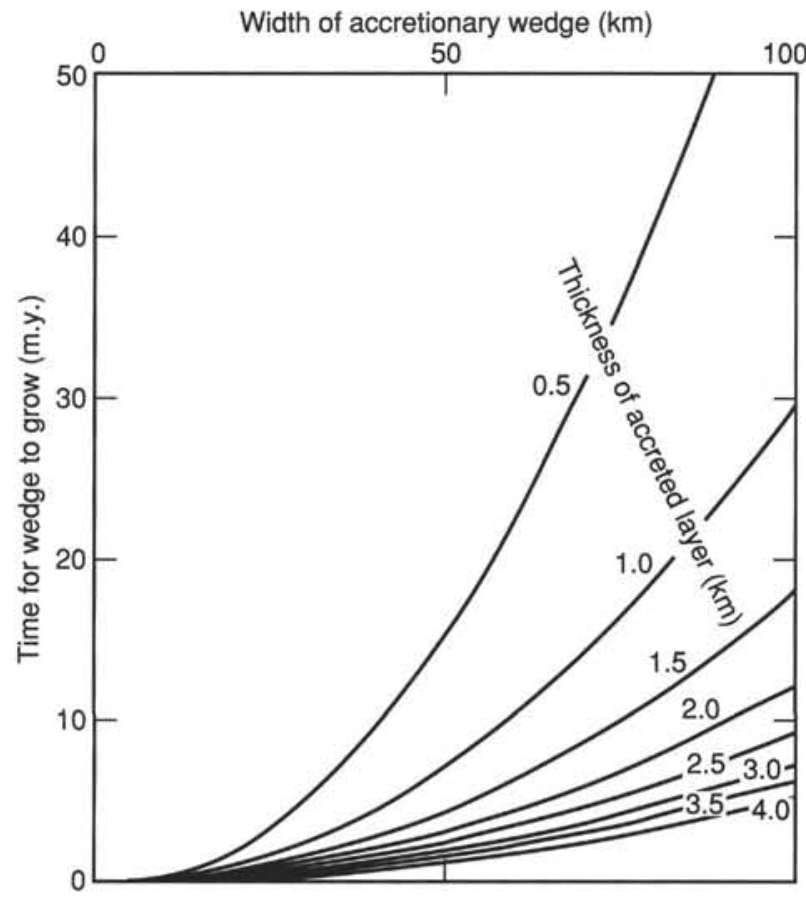

Figure 5. Graph illustrating the time taken to grow a wedge of given width from layers of different thicknesses. The eight curves show times of growth from layers of 0.5 to $4.0 \mathrm{~km}$ thickness. The taper of the wedge is $8.5^{\circ}$, the surface porosity is 0.6 , and $\lambda$ is 1.5 . The rate of plate convergence is $42 \mathrm{~km} / \mathrm{m}$.y.

driven fluid outflow from the margin is of exponential form with a surface porosity of 0.6 , and $1.5 \mathrm{~km}$ for the depth at which the porosity has declined to $0.6 / \mathrm{e}$. Using these parameters, the model predicts that it only takes 2.4 m.y. to accrete the whole of the accretionary wedge if the rate of subduction of the oceanic lithosphere is $42 \mathrm{~km} / \mathrm{m}$.y. (Fig. 5 ). This is clearly not what has occurred, because of the Eocene age of the sediments in the Tofino Basin overlying the landward end of 


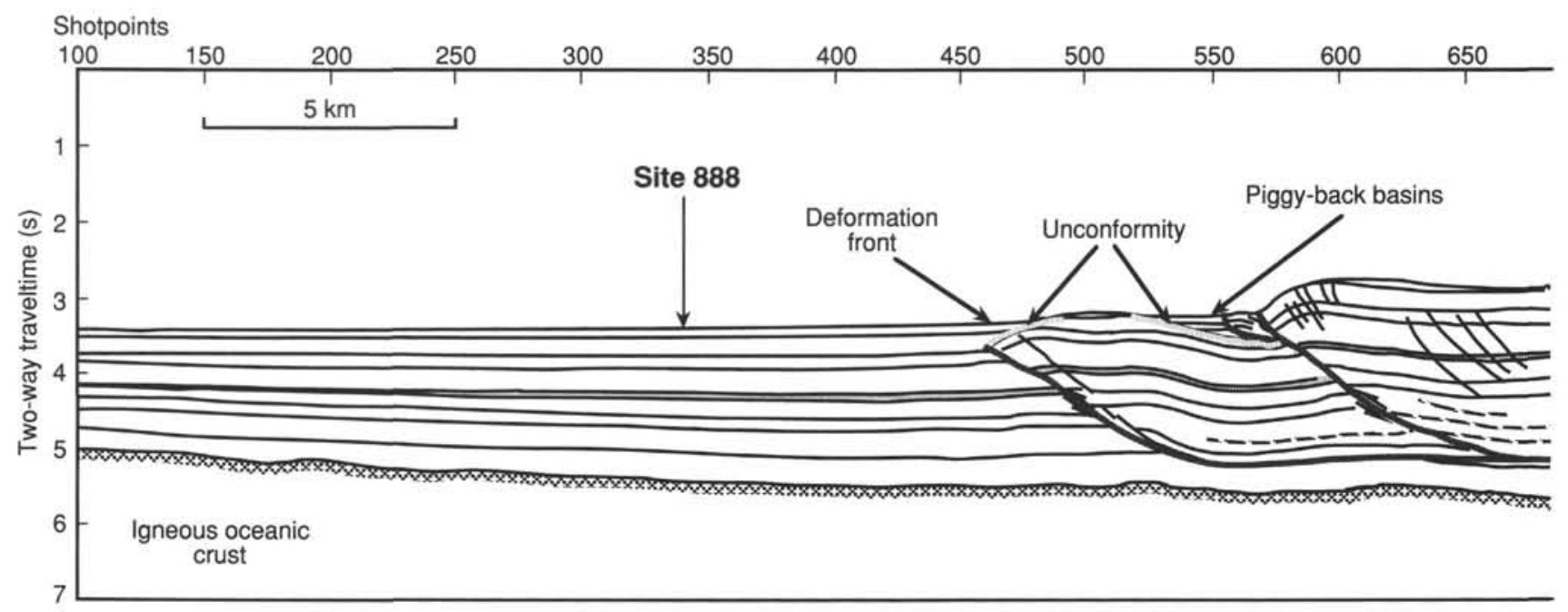

Figure 6. Interpretative line drawing of migrated seismic reflection section $89-04$, on which Site 888 is situated. The first three thrust slices of the accretionary wedge are rooted in a décollement that lies only a little above the base of incoming sediment sequence in the Cascadia Basin. The wedge landward of these first three thrust slices appears to have been accreted from above a shallower décollement, lying at a stratigraphic position close to the base of the well-layered sequence in the first three thrust slices. The style of the older accreted section is one of the shorter wavelength, more intensely deformed structures. This is overlain by a slope-cover sequence that is only mildly deformed.

the accretionary wedge. Even if one takes into account the sediment that is underplated beneath the Crescent Terrane, then it still requires less than 5 m.y. to accrete all the sediment, and, by implication, the underplated sediment was initially subducted beneath the toe of the accretionary wedge. Using a different porosity-depth function for the wedge (by substituting different values of $\phi_{0}$ and $\lambda$ into the right side of Eq. 2), in which the surface porosity is less and porosity decreases more rapidly with depth, makes little difference to the time required to build the wedge. A function with surface porosity of 0.5 and depth at which porosity is $0.5 / \mathrm{e}$ of $1.0 \mathrm{~km}$ only increases the time taken to build the wedge from 2.4 to $2.7 \mathrm{~m} . \mathrm{y}$.

It must be the case that in the past a thinner layer of sediment was accreted. Inspection of seismic reflection sections 89-04 and 89-08 shows clear evidence of this. Landward of the point where the gradient of the continental slope becomes greater, the wavelengths of structures in the wedge become much shorter, and undeformed reflectors can be traced up to $5 \mathrm{~km}$ beneath this more intensely deformed part of the wedge (Figs. 6-7). If an average thickness of $1 \mathrm{~km}$ is assumed for the accreted layer, then a period of $7.1 \mathrm{~m} . \mathrm{y}$. is required to accrete the sediment in the wedge (Fig. 5).

Site 889 , situated on seismic reflection line $89-08$, is about $24 \mathrm{~km}$ from the deformation front. If it is assumed that a thickness of 2.50 $\mathrm{km}$ of sediment has been accreted over the period since the accreted sediment at Site 889 was at the deformation front, then the length of that period is about 0.8 m.y. If the thickness of the accreted layer was initially $1.0 \mathrm{~km}$ and subsequently became $2.5 \mathrm{~km}$, then the length of the period following the accretion of the sediment at Site 889 totalled 1.05 m.y.: 0.76 m.y. when the layer was $1.0 \mathrm{~km}$ thick and 0.29 m.y. when the layer was $2.5 \mathrm{~km}$ thick.

Davis and Hyndman (1989) have also examined the budget of accreted sediment for the wedge off Vancouver Island. They showed that the thickness of the layer of accreted sediment before the Pleistocene must have been much less than its present thickness. They concluded, however, that all the wedge had been formed by accretion at the toe of the wedge and that the accreted layer was always very nearly the whole of the sedimentary section on the incoming plate. They derived an average thickness of $2.1 \mathrm{~km}$ for the layer accreted in the Pleistocene by assuming that all the wedge seaward of a steepening of the slope of the wedge about $35 \mathrm{~km}$ from the toe was accreted in the Pleistocene, and they estimated an average thickness of $0.9 \mathrm{~km}$ for the layer accreted between the Eocene and the Pleistocene. This is apparently at variance with what is presented here, but there is only one major difference between the two approaches, which is in the interpretation of how the sediment underlying the Tofino Basin and Crescent Terrane came to be emplaced. Davis and Hyndman (1989) stated that all the sediment was accreted at the toe of the wedge, but to get beneath the Crescent Terrane, the sediment must have "flowed" underneath by some unspecified mechanism, because it all lies landward of the Eocene deformation front and the overlying terrane is effectively intact. Similarly, the sediment in the deeper part of the section underneath the Tofino Basin west of the edge of the Crescent Terrane would also have had to "flow" under, following accretion at the toe, as there is no mechanism to thicken the section without disturbing the overlying basin other than that of underplating (subcretion), which Davis and Hyndman exclude. In the analysis presented here, the width of the wedge is taken to the most landward portion of the wedge that can have grown by accretion at the toe of the wedge since the Eocene (42 Ma), without invoking large-scale horizontal flow within the accretionary wedge. Consequently, the material beneath the Crescent Terrane and the deeper part of the section beneath the Tofino Basin is considered to have been subcreted.

The thicknesses of the accreted layer given by Davis and Hyndman (1989) are also the total thicknesses of sediment on the incoming plate, whereas the thicknesses given here are strictly those of the layer accreted at the toe of the wedge. The sediment beneath that layer is taken on the subducting oceanic lithosphere beneath the toe of the accretionary wedge to be subcreted further back or subducted deeper into the subduction zone. From the cross-sectional area of the more landward parts of the accretionary wedge, it appears that most of it is subducted.

Other differences are also apparent between the parameters used by Davis and Hyndman (1989) and those used in this analysis. Davis and Hyndman place the edge of the Crescent Terrane $75 \mathrm{~km}$ from the toe of the wedge, whereas in this study the distance taken from the section of Hyndman et al. (1990) is just over $50 \mathrm{~km}$ (see fig. 2 of the "Introduction" chapter and figs. 2 and 7 of Hyndman et al., both in this volume). The total cross-sectional area of the wedge used by Davis and Hyndman, including that beneath the Crescent Terrane, is 


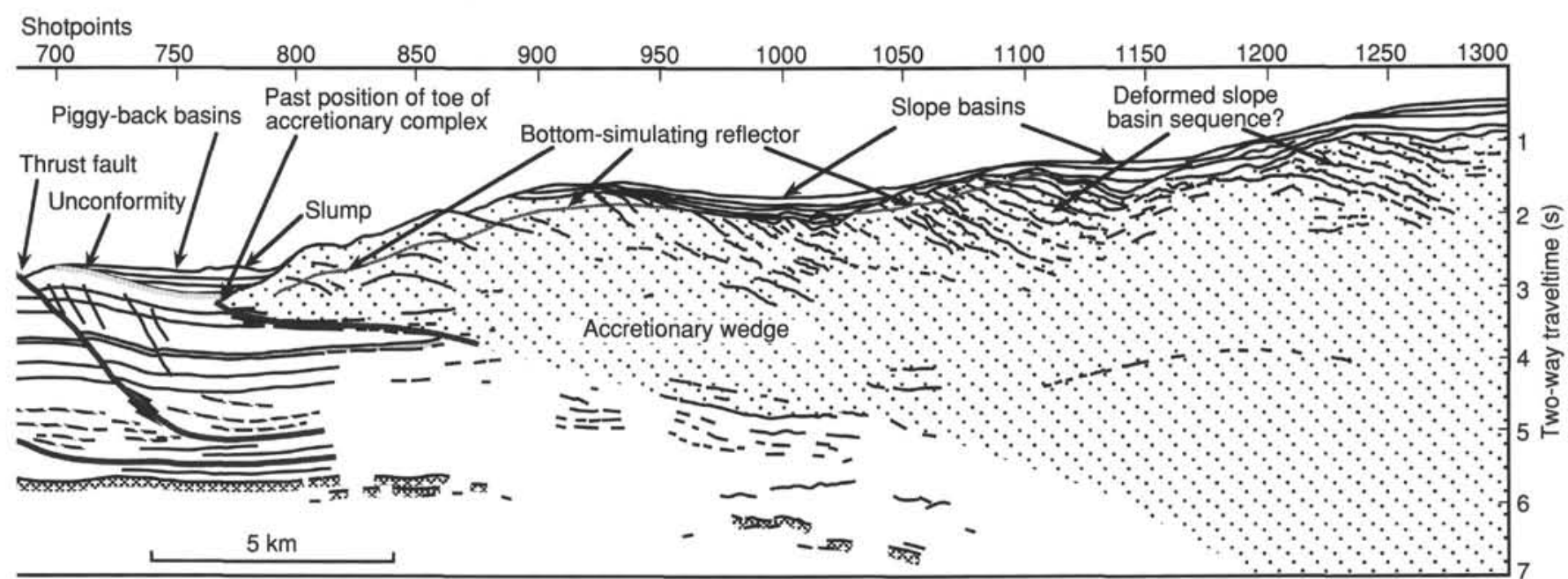

Figure 6 (continued).

$1070 \mathrm{~km}^{2}$. If the width of the wedge west of the Crescent Terrane is taken to be $75 \mathrm{~km}$ (cross-sectional area $=608 \mathrm{~km}^{2}$ ), following Davis and Hyndman (1989), then the time required to accrete a layer $2.5 \mathrm{~km}$ thick would be 5.5 m.y., a layer $1.0 \mathrm{~km}$ thick would be 16.5 m.y., and a layer $0.5 \mathrm{~km}$ thick would be $37 \mathrm{~m}$.y. (Fig. 5). The general conclusion is still that over the period since the Eocene ( $42 \mathrm{~m} . \mathrm{y}$.) the average thickness of the accreted layer is much less than $1 \mathrm{~km}$.

If the assumption of Davis and Hyndman (1989) that the first 35 $\mathrm{km}$ of the wedge (of cross-sectional area $=179 \mathrm{~km}^{2}$ ) was accreted in the Pleistocene (since 1.8 Ma) is adopted, then the average thickness of the accreted layer given by the model is $1.7 \mathrm{~km}$. This requires a change of thickness of the accreted layer to the present thickness of $2.5 \mathrm{~km}$ at some time over this period depending on its initial thickness, as was demonstrated above with respect to the time of accretion of the section at Site 889 (about $1 \mathrm{Ma}$ ).

\section{APPLICATION TO THE OREGON MARGIN}

Off Oregon, the direction of subduction is significantly oblique to the margin (Fig. 8), and so the rate of subduction normal to the margin is about $32 \mathrm{~km} / \mathrm{m}$.y. The width of the accretionary wedge up to the edge of the forearc basin on the continental shelf is $60 \mathrm{~km}$. It is about $40 \mathrm{~km}$ to that segment of the slope where upper Paleocene to lower Eocene sediments crop out at the seabed. If the width of the wedge is taken as $40 \mathrm{~km}$, with an angle of taper of $8.5^{\circ}$ (estimated from the taper angle over the first $5-10 \mathrm{~km}$ shown on seismic reflection sections), and the thickness of the accreted layer is $1.5 \mathrm{~km}$ as shown at the current toe of the wedge, then the time required to build the wedge is $3.3 \mathrm{~m} . y$. (Table 1 ). If an estimate of the angle of taper of $12^{\circ}$, taken from the cross-section of Snavely et al. (1980) is used, then the time required is $5.3 \mathrm{~m} . \mathrm{y}$. A time of $12.2 \mathrm{~m} . \mathrm{y}$. is obtained if a width for the wedge of $60 \mathrm{~km}$ is used with a taper angle of $12^{\circ}$. The age of the oceanic lithosphere at the toe of the wedge when it was $60 \mathrm{~km}$ east of its present position was $30 \mathrm{Ma}$ (assuming that its age is $9 \mathrm{Ma}$ at the present toe, and that the 452-km-long segment of oceanic lithosphere from which sediment was stripped to form the wedge was generated at the mid-ocean ridge at $21 \mathrm{~km} / \mathrm{m}$.y.). This age is inconsistent with the presence of upper Paleocene to lower Eocene sediments in the margin east of $40 \mathrm{~km}$ from the toe of the wedge. Similarly, if the width of the active wedge is taken as $40 \mathrm{~km}$, then the age of the oceanic lithosphere at the toe, when it was $40 \mathrm{~km}$ further east, was $19 \mathrm{Ma}$, inconsistent with the presence of lower Oligocene to Miocene sediment in the wedge west of $40 \mathrm{~km}$ from the toe.
It is clear that in the past a substantial amount of sediment has been lost from the wedge or that the average thickness of the accreted layer was much less. Reducing the thickness of the accreted layer to $0.6 \mathrm{~km}$ allows the wedge to begin accretion at $36 \mathrm{Ma}$ (the beginning of the Oligocene) on oceanic lithosphere with an age of $67 \mathrm{Ma}$. This would satisfy the age constraints for a $60-\mathrm{km}$-wide wedge, and also for a $40-\mathrm{km}$-wide wedge, which would begin growth at $15.5 \mathrm{Ma}$ on oceanic lithosphere of age $34.5 \mathrm{Ma}$ (early Oligocene). If one takes the growth of the wedge to have begun at $36 \mathrm{Ma}$ from $60 \mathrm{~km}$ east of the present toe, then the model predicts that the wedge up to $40 \mathrm{~km}$ east of the present toe was accreted since $16.5 \mathrm{Ma}$ from oceanic lithosphere younger than $34.5 \mathrm{Ma}$ in age when the wedge was $45 \mathrm{~km}$ wide.

The accretionary composition of the wedge could be explained by one of the following scenarios:

1. A thin layer of sediment was accreted, because (a) the sediment thickness on the subducted plate was smaller until recently, and/or (b) most of the sediment has been subducted.

2. Extensive mass wasting of the surface of the wedge resulted in the net addition of sediment equivalent to the accretion of a relatively thin layer. Consequently, much of the sediment in the wedge has been cycled through the wedge more than once.

3. There have been episodes of substantial tectonic erosion.

Table 1. Growth of the accretionary wedge off Oregon.

\begin{tabular}{ccccc}
\hline $\begin{array}{c}\text { Width } \\
(\mathrm{km})\end{array}$ & $\begin{array}{c}\text { Taper } \\
\text { angle } \\
\text { (degrees) }\end{array}$ & $\begin{array}{c}\text { Layer } \\
\text { thickness } \\
(\mathrm{km})\end{array}$ & $\begin{array}{c}\text { Time } \\
\text { to grow } \\
(\mathrm{m} . \mathrm{y} .)\end{array}$ & $\begin{array}{c}\text { Age of } \\
\text { oceanic } \\
\text { lithosphere } \\
(\mathrm{Ma})^{\mathrm{a}}\end{array}$ \\
\hline 40 & 8.5 & 1.5 & 3.3 & 16.0 \\
40 & 12.0 & 1.5 & 5.3 & 19.0 \\
60 & 12.0 & 1.5 & 12.2 & 30.0 \\
40 & 8.5 & 0.6 & 10.4 & 27.0 \\
40 & 12.0 & 0.6 & 15.5 & 34.5 \\
60 & 12.0 & 0.6 & 36.0 & 67.0 \\
\hline
\end{tabular}

Notes: The rate of subduction is $32 \mathrm{~km} / \mathrm{m} . \mathrm{y}$. The surface porosity is 0.6 , and $\lambda$ is 1.5 .

a Age of oceanic lithosphere at the toe of the accretionary wedge when it began to grow. It is assumed that the oceanic lithosphere was generated at a half spreading rate of $21 \mathrm{~km} / \mathrm{m}$.y. and that its age at the present toe of the wedge is $9 \mathrm{Ma}$. 


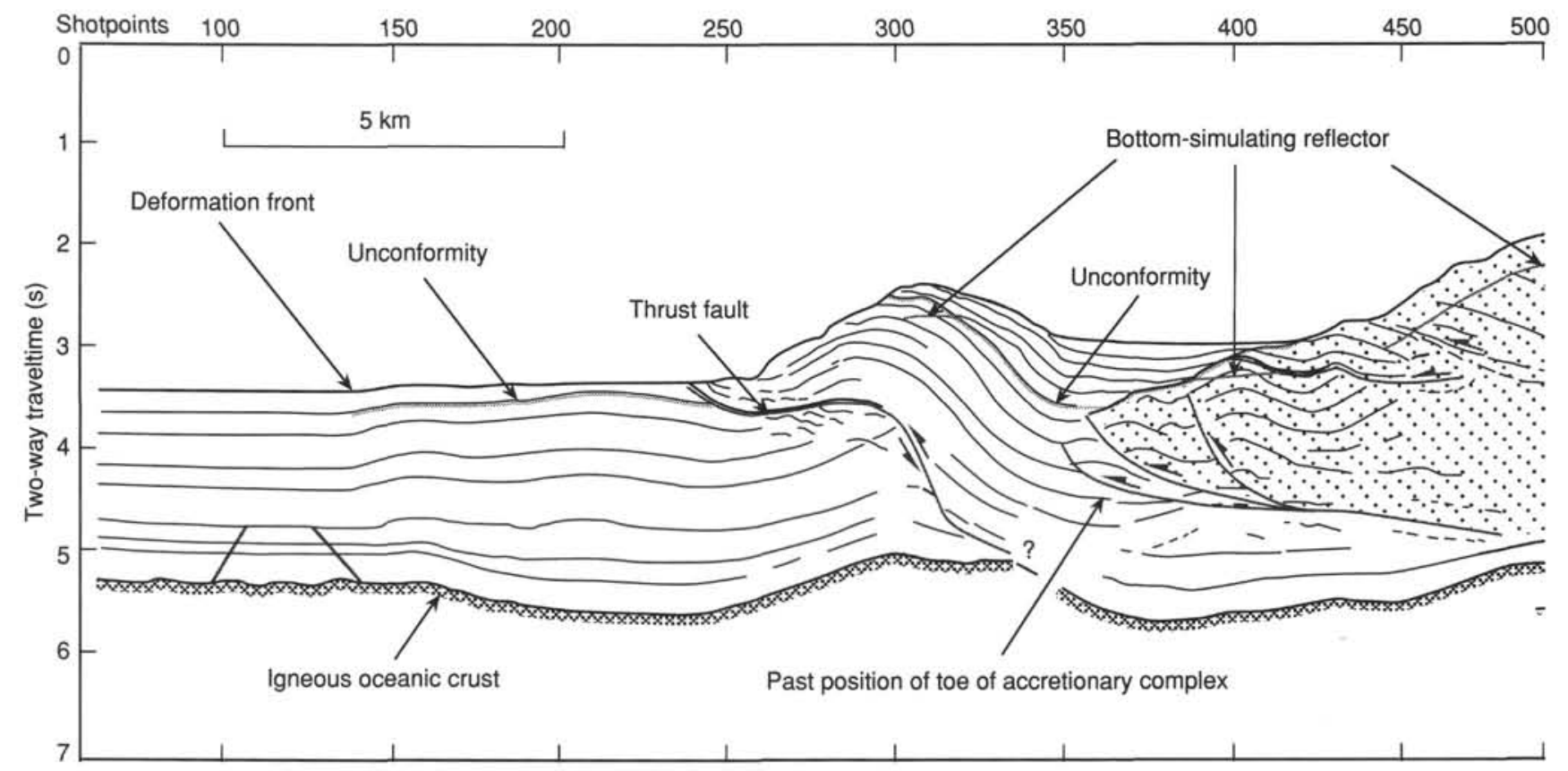

Figure 7. Line drawing of migrated seismic-reflection section $89-08$, showing the broadly folded thrust sheets of the lower slope, and undeformed Cascadia Basin deposits to the southwest. The décollement beneath these thrust sheets lies close to the surface of the igneous oceanic basement. Most of the reflectors within the accretionary wedge to the northeast are short and commonly nonlinear, indicative of poorly imaged short-wavelength structures formed above a shallow décollement. Site 889 , on the mid-slope of the wedge, penetrates seismically incoherent accreted sediments and overlying slope-drape and slope-basin sediments.

It has been suggested that there have been several phases of accretion and that the most recent phase began in the late Miocene (Snavely, 1987; Duncan and Kulm, 1989). The width of the frontal segment of the wedge containing late Miocene and younger sediments is about $30 \mathrm{~km}$. This segment of the wedge could have been accreted since $10 \mathrm{Ma}$ from a $0.6-\mathrm{km}$-thick layer, consistent with gradual, virtually continuous growth. The total width of the wedge would have been $52 \mathrm{~km}$ at $10 \mathrm{Ma}$. To accrete this segment of the wedge from a layer $1.5 \mathrm{~km}$ thick only requires $3.1 \mathrm{~m} . \mathrm{y}$. Therefore, a change to accretion of a layer $1.5 \mathrm{~km}$ thick must have been quite recent, unless there have been episodes of tectonic erosion over the past $10 \mathrm{~m} . \mathrm{y}$.

Site 892 is $17.5 \mathrm{~km}$ from the toe of the wedge (Fig. 9). The youngest accreted sediments are of late Pliocene age. If we adopt a wedge taper of $8.5^{\circ}$, as shown by the seismic reflection section, then the model predicts a youngest age for these sediments being at the toe of the wedge of $1.1 \mathrm{Ma}$, which is too young, as no Pleistocene sediments are present. If the accretion of only the first thrust slice in the wedge has been from a layer $1.5 \mathrm{~km}$ thick, comprising the first $7.5 \mathrm{~km}$ of the wedge, which would have taken $0.3 \mathrm{~m} . \mathrm{y}$., then the accretion of a layer $0.6 \mathrm{~km}$ thick over the preceding $1.75 \mathrm{~m}$.y. would bring material at the toe of the wedge at $2.05 \mathrm{Ma}$ to the position of Site 892 . This is compatible with the much less open style of deformation landward of the second thrust, which is suggestive of the accretion of a thin layer.

At the toe of the wedge, it is useful to know the rates at which structures such as the first thrust-anticline are forming. The continuum model used here for the analyses of wedge growth loses the validity of its approximation of internal deformation and compaction within the wedge when applied to individual structures, but it does provide some helpful insights. The average rate of advance of the toe of the wedge into the incoming sediments is given by the model as $37 \mathrm{~km} / \mathrm{m}$.y. (the rate of subduction is $32 \mathrm{~km} / \mathrm{m} . \mathrm{y}$.), but the toe does not advance continuously. It moves forward episodically as each new frontal thrust is developed. Over the cycle of development of a new thrust and its anticlinally folded thrust sheet, however, the advance of the wedge should be close to that predicted by the continuum model.
The spacing between the first and second thrusts in the wedge is about $7.5 \mathrm{~km}$. The model predicts that the former toe of the wedge reaches a position $7.5 \mathrm{~km}$ landward of the toe of the wedge after $0.3 \mathrm{~m}$.y., which is attained after $9.6 \mathrm{~km}$ of plate convergence, equivalent to an advance of the toe of the wedge relative to the Juan de Fuca Plate of $11.1 \mathrm{~km}$. This yields a displacement between two once horizontally coincident points above and below the décollement of $3.7 \mathrm{~km}$. The displacement measured on the frontal thrust is $2.7 \mathrm{~km}$ (see "Seismic Stratigraphy" section, "Site 891 " chapter, this volume). The difference may have been taken up by internal shortening within the wedge between $7.5 \mathrm{~km}$ landward of the toe and $5 \mathrm{~km}$ landward of the toe, where the frontal thrust breaks to the surface from the décollement, although it does not appear to have thickened sufficiently for this. The model predicts that material at the equivalent position of the toe at $0.25 \mathrm{Ma}$ is now $6.5 \mathrm{~km}$ landward of the toe and has been displaced $2.8 \mathrm{~km}$ relative to the underthrust sequence beneath the décollement. If it is assumed that the wedge seaward of this position has undergone little internal shortening, then the observed displacement on the frontal thrust will be produced, with accompanying uplift and erosion of the upthrust sequence. Thus, the frontal anticline is unlikely to be older than $0.3 \mathrm{Ma}$ and probably began to form about $0.25 \mathrm{Ma}$.

\section{CONCLUDING REMARKS}

The structure and age distribution of accreted sediment in both the wedges off Vancouver Island and Oregon are consistent with the accretion of a thick sequence of sediment for a period no longer than $1 \mathrm{~m} . \mathrm{y}$. Over the period since the formation of these wedges in the Eocene, the average thickness of the layer of sediment that had been accreted has been about $0.5 \mathrm{~km}$. In both cases, any sediment subcreted (underplated) to the system landward of the boundary of the accretionary wedge with the forearc basin has not contributed to the growth of the wedge seaward of the forearc basin, and would have been derived from the layer of sediment that lay beneath the accreted layer and which had been subducted beneath the accretionary wedge. 


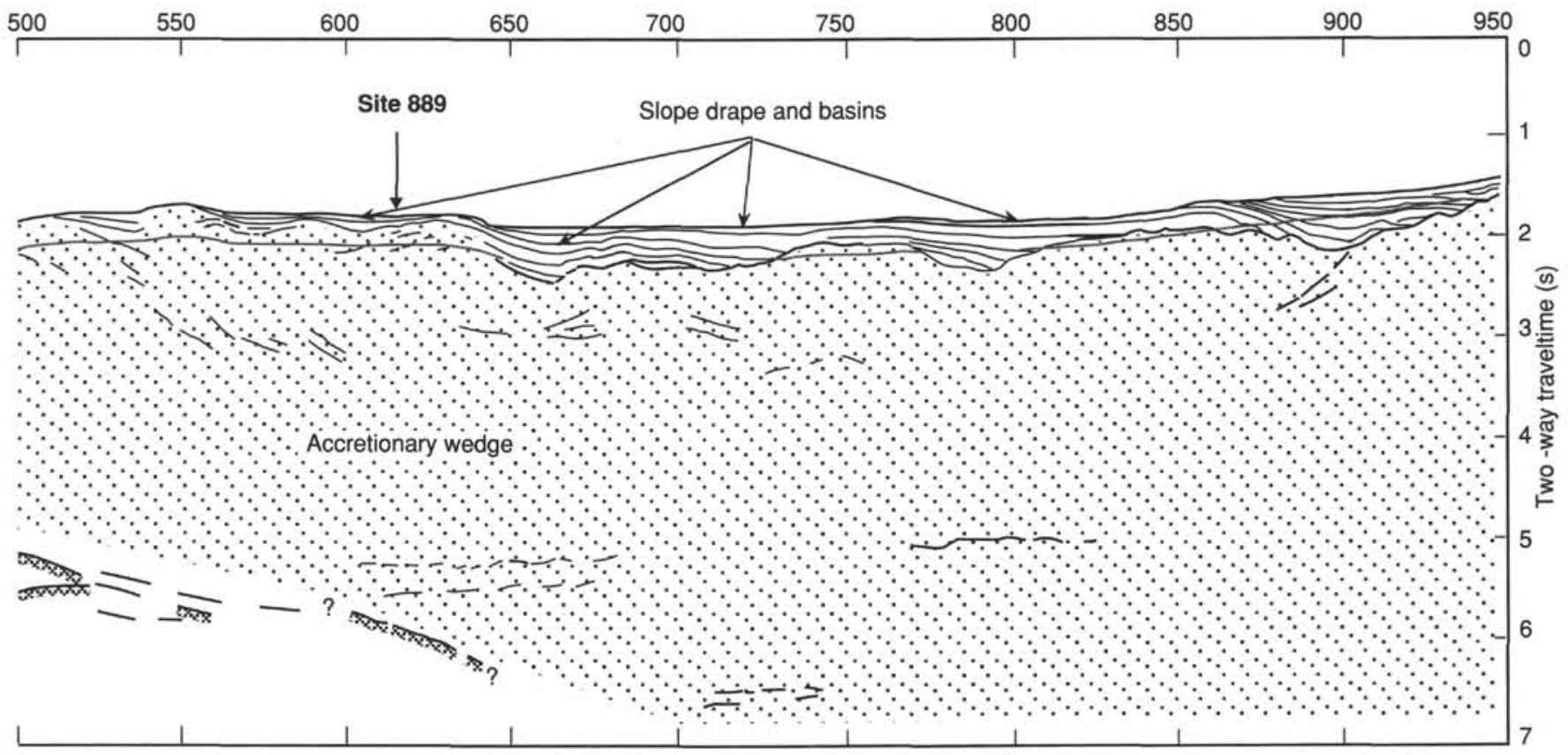

Figure 7 (continued).

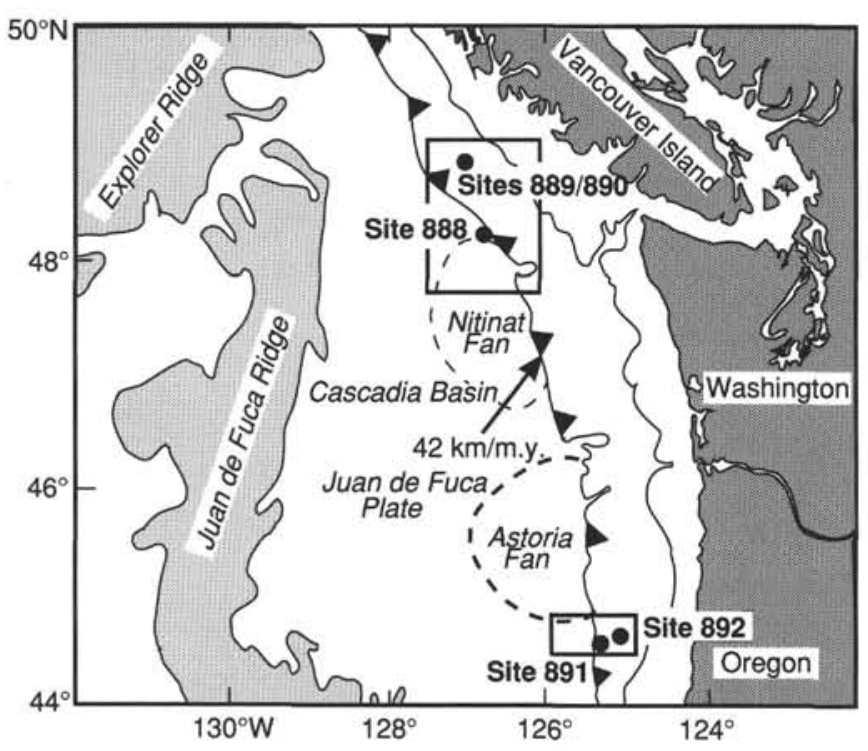

Figure 8. Location map of the Cascadia Margin, showing the convergent plate motion, major physiographic features in the Cascadia Basin (overlying the Juan de Fuca Plate), the position of the continental margin, and the positions of drilling sites off Vancouver Island and Oregon.

\section{REFERENCES*}

Bekins, B.A., and Dreiss, S.J., 1992. A simplified analysis of parameters controlling dewatering in accretionary prisms. Earth Planet. Sci. Lett., 109:275-287.
Davis, E.E., and Hyndman, R.D., 1989. Accretion and recent deformation of sediments along the northern Cascadia subduction zone. Geol. Soc. Am. Bull., 101:1465-1480.

Davis, E.E., Hyndman, R.D., and Villinger, H., 1990. Rates of fluid expulsion across the northern Cascadia accretionary prism: constraints from new heat flow and multichannel seismic reflection data. J. Geophys. Res., 95:88698889.

Duncan, R.A., and Kulm, L.D., 1989. Plate tectonic evolution of the Cascades arc-subduction complex. In Winterer, E.L., Hussong, D.M., and Decker, R.W. (Eds.), The Eastern Pacific Ocean and Hawaii. Geol. Soc. Am., 413-438.

Ferguson, I.J., Westbrook, G.K., Langseth, M.G., and Thomas, G.P., 1993. Heat flow and thermal models of the Barbados Ridge accretionary complex. J. Geophys. Res., 98:4121-4142.

Hyndman, R.D., Yorath, C.J., Clowes, R.M., and Davis, E.E., 1990. The northern Cascadia subduction at Vancouver Island: seismic structure and tectonic history. Can. J. Earth Sci., 27:313-319.

Le Pichon, X., Henry, P., and Lallement, S., 1990. Water flow in the Barbados accretionary complex. J. Geophys. Res., 95:8945-8967.

Snavely, P.D., Jr., 1987. Tertiary geologic framework, neotectonics, and petroleum potential of the Oregon-Washington continental margin. In Scholl, D.W., Grantz, A., and Vedder, J.G. (Eds.), Geology and Resource Potential of the Continental Margin of Western North America and Adjacent Ocean Basins-Beaufort Sea to Baja California. Circum-Pac. Counc. Energy Mineral Resour., 305-336.

Snavely, P.D., Jr., Wagner, H.C., and Lander, D.L., 1980. Geologic cross section of the central Oregon continental margin. Geol. Soc. Am., Map and Chart Ser, MC-28J.

"Abbreviations for names of organizations and publication titles in ODP reference lists follow the style given in Chemical Abstracts Service Source Index (published by American Chemical Society).

\section{Ms 146IR-011}




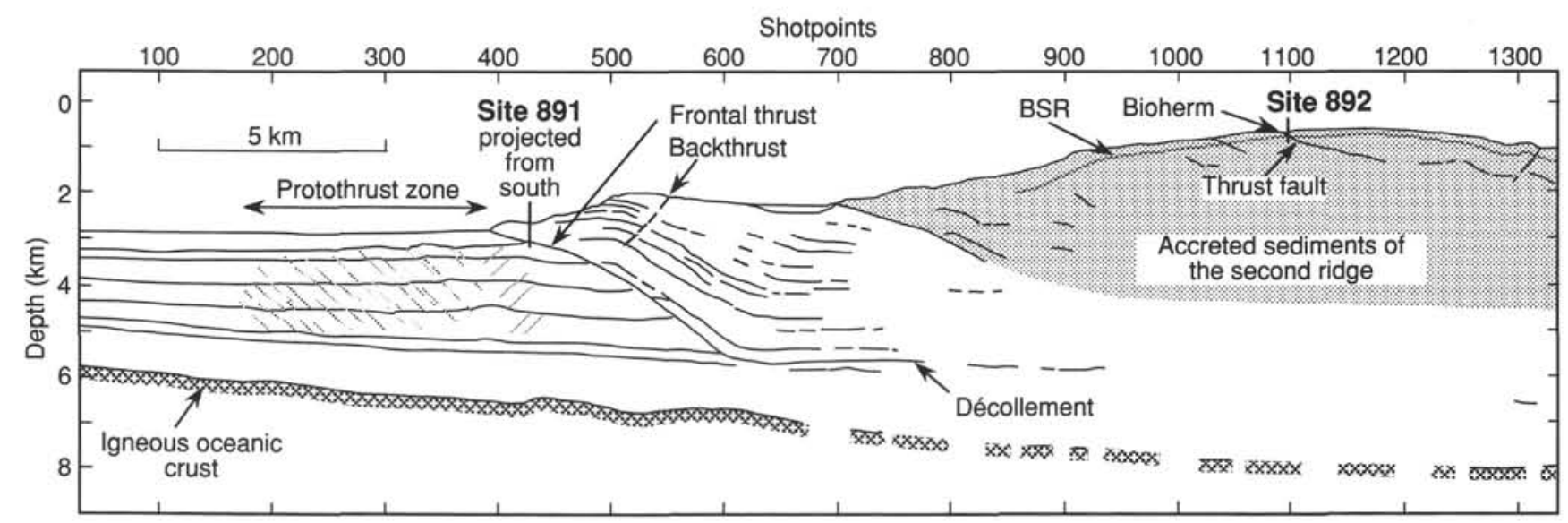

Figure 9. Depth-converted migrated seismic-reflection section OR-9, showing flat-lying Cascadia Basin deposits (shotpoints 43-150), the proto-deformation zone characterized by blind thrusts (shotpoints 150-400), the ridge of the lower slope underlain by a seaward-verging thrust fault (shotpoints $400-600$ ), and the second ridge (shotpoints 725-1355). The position of Site 892 is indicated. The structural position of Site 891 has been projected from the actual drilling location, $3 \mathrm{~km}$ to the south. 